\title{
O culto às ideias em Germán Carrera Damas
}

\author{
The cult of ideas in Germán Carrera Damas
}

\section{RESUMO:}

A fórmula do "culto a Bolívar", elaborada por Germán Carrera Damas em seu livro homônimo, é uma das leituras mais usais e originais sobre o passado venezuelano. Nela, a permanência de imagens do herói no cenário político, ao longo da história, é percebida como uma corruptela do percurso histórico que a nação deveria perseguir. A lógica desse argumento deriva diretamente de um embasamento na História das ideias, o que a leva a uma sequência de problemas de ordem interpretativa e metodológica. $O$ intuito do presente trabalho é debater essas complicações, tendo em vista a centralidade do pensamento de Carrera Damas para a escrita da história venezuelana. Sob o escrutínio das críticas que Elias Palti tece à História das ideias na América Latina e dos estudos de linguagens políticas de John Pocock, buscase, aqui, desconstruir duas percepções da historiografia de Carrera Damas: 1. que o culto a Bolívar esteja implicado no atraso sociopolítico venezuelano; e 2 . que esse fenômeno possa ser reduzido a uma ideologia instrumentalizada para dominação social.

\section{PALAVRAS CHAVE:}

Bolivarianismo; Historiografia hispano-americana; História das ideias

\author{
Matheus Amilton Martins \\ https://orcid.org/0000-0002-2067-7508 iD
} htps:/orcid.org/0000-0002-2067-7508(D)

\section{ABSTRACT:}

The formula of the "cult of Bolivar" elaborated by Germán Carrera Damas in his homonym book is one of the most usual and original readings of the Venezuelan past. Carrera Damas argues that the permanence of images of the hero in the political scene, throughout Venezuelan history, is perceived as a corruption of the historical path that a nation should pursue. The logic of this argument is directly derived from the History of ideas, leading to a several problems of interpretative and methodological order. This article seeks to discuss these complications, considering the centrality of Carrera Damas' thinking for the writing of Venezuelan history. From Elias Palti's criticism of the History of ideas in Latin America and John Pocock's studies of political languages, we intend to deconstruct two perceptions of Carrera Damas historiography: first, that the cult of Bolivar is implicated in the Venezuelan sociopolitical backwardness; and secondly, that this phenomenon can be reduced to an instrumentalized ideology for social domination.

\section{KEYWORDS:}

Bolivarianism;

Hispanic-American

historiography; History of Ideas 


\section{Ao autor imprescindível, uma problematizaçāo necessária}

A vigência do legado político-intelectual de Simón Bolívar, em suas inúmeras reinvenções e ressignificações, foi um fenômeno que não passou desapercebido à escrita da história venezuelana. Desde o campo da história pátria oitocentista, empenhado na manutenção e/ou reatualização do imaginário bolivariano, passando por esforços revisionistas - a exemplo de José Luis Salcedo-Bastardo (1976), que tentou descolar Bolívar de seu status divinizado para localizá-lo no meio intelectual da independência -, até a produção crítica das duas gerações de historiadores mais enfáticas no projeto de subversão do bolivarianismo, os espólios do Libertador foram colocados como um dos eixos centrais na escrita do passado nacional.

Para se ter uma noção da dimensão da produção historiográfica mais recente relacionada à crítica ao culto a Bolívar, cabe considerá-la, a partir de seu contexto político, em duas gerações. A primeira, posterior à ditadura militar de Marco Pérez Jimenez (1948-1959), se relacionou a uma conjuntura de restabelecimento e manutenção dos preceitos democráticos na Venezuela (período da $4^{a}$ República): encontram-se aqui as obras de Yolanda Salas de Lecuna (1987) e Luis Castro Leiva (1985; 1991). Já a segunda geração convive com a ascensão política de Hugo Chávez e sua nova leitura do bolivarianismo (período da $5^{a}$ República). Nesse grupo há uma propensão à dissidência política em relação aos governos chavistas; entre seus principais autores, destacam-se Elías Pino Iturrieta (2003), Manuel Caballero (2007), Ana Teresa Torres (2009) e Tomás Straka (2009).

Germán Carrera Damas (1930- ) e sua obra têm uma posição de referência e centralidade para ambos os grupos. ${ }^{1} \mathrm{Em}$ sua trajetória acadêmica, o autor tem desenvolvido pesquisas sobre o bolivarianismo desde seu doutorado, na Universidad Central de Venezuela (UCV), em 1969. Ademais, ocupou a Cátedra Simón Bolívar na University of Cambridge (Reino Uni- 
do) e na Universität zu Köln (Alemanha), destacando-se como um dos mais reconhecidos historiadores no meio universitário nacional. Por outro lado, costumeiramente atua em interlocuções políticas, a exemplo de seu papel como porta-voz de uma oposição intelectual aos governos de Hugo Chávez (19992013). A esses aspectos soma-se o potencial de seus trabalhos em oferecer explicações, com embasamento histórico, às dinâmicas sociopolíticas do cotidiano venezuelano.

Um dos principais focos de seus estudos diz respeito à preponderância da ideologia bolivariana no campo da política venezuelana. É sobre esse tema que o autor versa em El culto a Bolívar: um esbozo para historia de las ideas en Venezuela (2003), publicado originalmente em 1970, que viria se tornar referência para as discussões sobre os usos da figura de Bolívar que, a partir de então, povoaram a historiografia venezuelana. Nessa obra, estabeleceu uma investigação direta e sistemática do que, ao longo de seus estudos, considerou um produto ideológico da historiografia oficial venezuelana, comprometido com a inconformidade das condições democráticas locais: o culto ao herói nacional convertido em segunda religião (CARRERA DAMAS 2003, p. 64).

Em sua análise, elaborou uma explicação geral da história venezuelana. Considerando a ideologia como expressão da realidade histórica e síntese de sua pluralidade (2003, p. 25), Carrera Damas ultrapassou o dualismo apologia-acusação, atribuído à história tradicional, para se preocupar em demonstrar as distorções na consciência histórica nacional - produzidas pelo culto a Simón Bolívar - e seus efeitos no âmbito político. Esse argumento teve um lugar oportuno, no contexto de publicação de El culto a Bolívar, relacionado à ação política do autor. O próprio Carrera Damas explicou a conjuntura em entrevista a Anatólio Medeiros Arce e Losandro Antonio Tedeschi:

Yo comencé a trabajar en eso ya sistemáticamente cuando regresé del exilio. Estuve diez años exiliado durante el gobierno de Pérez Jiménez. Regresé aquí en 58 [1958] y me encontré con que los hombres que estaban planteando de nuevo la democra- 
cia en Venezuela estaban utilizando las mismas ideas que había usado la dictadura. Y aquello sí me preocupó. Porque veía que íbamos por un camino malo, en el sentido de que esas ideas de Bolívar corresponden a otro tiempo y fueron pervertidas y utilizadas para justamente dominar y controlar a la sociedad, no para un desarrollo democrático. $Y$ yo escribí este libro para alertarlo, o mejor dicho, con la emoción de que yo iba a alertar a estos dirigentes políticos. (ARCE; TEDESCHI 2015, p. 203)

Além de apontar os objetivos originais da obra, o depoimento dá margem a uma avaliação de seu escrito. A necessidade de percorrer um vasto arco temporal - da consolidação da independência às ditaduras do século $X X$ - em busca de uma interpretação geral para os efeitos da centralidade do culto heroico na vida pública, foi ocasionada pela possibilidade de reproduções da inadequação entre ideias e realidade no seu presente. Carrera Damas, portanto, escreveu sobre o culto a Bolívar especialmente preocupado com as potenciais repercussões negativas do bolivarianismo para sua contemporânea República Liberal Democrática², de modo que o cerne de sua explicação emanava de suas escolhas metodológicas, em especial do uso de premissas que a História das ideias desenvolveu nos estudos sobre a América Latina. Logo, muitas de suas críticas ao culto heroico provinham da visão idealista que professou em seus escritos. Um exemplo pode ser visto na fórmula da impossibilidade de desenvolvimento da democracia-liberal (ideia modernizante) sob a égide do mesmo bolivarianismo que envernizara as ditaduras venezuelanas do século XX (atavismo).

Carrera Damas buscou nas contradições da história política nacional "[...] a las condiciones en que se gesto el culto, a sus manifestaciones e al sentido que se ha dado históricamente" (CARRERA DAMAS 2003, p. 19, grifo nosso). Suas conclusões sobre esse fenômeno podem ser descritas em duas proposições que continuam influenciando outros estudiosos dedicados à investigação do culto:

\section{2 - Contexto pós- -ditadura de Perez Jiménez (1952-1958), definido no Pacto de Puntofijo (1958) como um acordo, entre eli- tes políticas, que con- templou o respeito aos resultados eleito- rais e a formação de governos de coalizão (Cf. SUÁREZ FIGUE- ROA 2006).}


1. Existem intenções de manipulação da consciência popular contidas na apropriação do culto por parte do Estado: a transformação de culto de un pueblo para culto para el Pueblo está centrada num processo de institucionalização de símbolos e ritos por parte do Estado, isto é, na adesão de uma série de governos a uma integração das manifestações do culto em sua estrutura administrativa, dotando o discurso estatal de capilaridade ideológica essencial para agir sobre a consciência popular a serviço da imposição de quaisquer políticas oficias (CARRERA DAMAS 2003, p. 308).

2. O surgimento do culto se deveu a uma necessidade histórica, atendendo a condições específicas do não cumprimento das promessas sociais da emancipação: o culto não é fruto do romantismo dos literatos venezuelanos, muito menos do patriotismo exaltado; ele é uma necessidade histórica com objetivos implícitos de ocultar o fracasso social da gesta libertadora e retardar a formulação de uma consciência histórica crítica a essa frustração. Nesse aspecto, segundo o autor, o culto mostra-se funcional até hoje (CARRERA DAMAS 2003, p. 42).

Cabe expor que suas colocações sobre as decorrências do culto como fenômeno de dominação social ocupam um lugar de validade historiográfica e política. Sua leitura ganha novo lastro na medida em que convive com a ascensão política dos governos Hugo Chávez (1999-2013), embasados num programa político intitulado alternativa bolivariana, ${ }^{3}$ definido por Chavéz como antítese dos valores político-econômicos neoliberais identificados com a República Liberal Democrática e, portanto, disposto a encerrá-la fundando uma nova era. A interpretação da história recente da Venezuela no discurso chavista solidifica essa compreensão:

En este siglo, durante la última década de gobierno del General Gómez, fue incubándose un modelo político al que perfectamente pudiéramos llamar "el modelo adeco", fundamentado especialmente en la explotación petrolera (en 1926 ya el petróleo
3 - A oposição intelectual ao chavismo tende a definir o bolivarianismo de Chavéz como elementos de uma democracia popular em conjunção a um caudillismo e a um autoritarismo militarista de cariz marxista-leninista. 
había desplazado al café como primer producto de exportación), en el populismo y en el autoritarismo. El "modelo adeco" irrumpió el 18 de octubre de 1945; echó sus bases en el Trienio 45-48, para ser desplazado durante una década y reaparecer en 1958, a la caída del gobierno del General Marcos Pérez Jiménez. Ahora sí había venido para quedarse. Desde entonces el nefasto modelo pisó el acelerador al proceso de sustitución de importaciones, profundizando el rentismo petrolero y la dependencia, sobre un pacto político cupular-partidista al que se conoce como "Pacto de Puntofijo", reforzado desde ese momento por el calderismo copeyano, cómplice, a pesar de su papel de actor de reparto, en el festín. El "Modelo Adecopeyano"devino, como tenía que ocurrir, en una crisis avalancha que hoy es ya una verdadera catástrofe moral, económica, política y social. Es histórica e irreversible. Conjuntamente con el Pacto de Puntofijo, que lo hizo posible, están no solamente agotados, sino que se encuentran ahora en la fase terminal de su triste historia y con ellos se hunde también el modelo económico colonialista-dependiente. (CHAVÉZ FRIAS 2014, p. 18)

Destituído o modelo adecopeyano, ${ }^{4}$ a alternativa bolivariana ocuparia o lugar de reformulação do sistema político a partir de fundamentos filosóficos (CHAVÉZ FRIAS 2014, p. 22). A ênfase em refundar e reconstituir o Poder Nacional denota que os valores de legitimidade para Chavéz estavam envolvidos com o recurso ao passado identificado com o projeto de Simón Bolívar para a Venezuela.

Em concordância com o que destaca Ana Teresa Torres, numa das mais recentes revisões bibliográficas sobre os estudos do culto a Bolívar, é justamente pelo remake chavista do bolivarianismo que a obra de Carrera Damas chegou ao ápice de sua popularidade, ultrapassando, inclusive, a fama que logrou em seu contexto de publicação, mais restrita ao âmbito acadêmico (TORRES 2009, p. 56). Não foi à toa que Manuel Caballero, em duras críticas ao chavismo, no livro Por qué no soy bolivariano: una reflexión antipatriótica (2007), citou a obra de Carrera Damas para convalidar sua argumentação:

Treinta y tres años después de su El culto a Bolívar, Gérman Damas publica Una ideología de reemplazo donde, (sin come-
4 - Com tal modelo, Chavéz se refere à aliança entre os partidos Ación Democrática (AD) e Comité de Organización Política Electoral Independiente (COPEI), firmada no Pacto de Puntofijo (1958). 
ter la habitual inelegancia de decir, como los gitanos de feria: "iYo lo había dicho!"), se sienta a la puerta de aquella primera tienda y ve pasar en ésta, no el cadáver de su enemigo, sino por desgracia, su cuerpo no por verdoso y putrefacto, menos vivito y coleando: de aquel culto que aún si se creía inocuo no dejaba de llevar en sí el germen de su peor peligro, el militarismo vestido con el uniforme de gala del Libertador; se ha pasado hoy, a lo que el autor llama de "bolivarismo-militarismo". (CABALLERO 2007, p. 157)

Os estudos de Carrera Damas parecem seguir fornecendo respostas satisfatórias às transformações da política e sociedade venezuelana, inclusive num tom quase premonitório. Outros, a exemplo de Elias Pino Iturrieta (2003), já apontavam para a importância do alerta emitido pelo autor ainda na década de 1960, embora especulasse novas questões devido ao chavismo:

[...] agotar el tema de su liturgia obligaría a un estudio de nunca acabar, si se pone uno tras la pista de todo lo que se ha publicado en sentido apologético. Por fortuna, ya intentó con éxito la faena Germán Damas en El culto a Bolívar, una obra de 1969 que se debe consultar con atención cuando los ojos quieran detenerse en las preces que el pueblo venezolano y pueblos parecidos dirigen a quien estiman como luz y salvación.

Ahora [con el chavismo] se ofrecen los testimonios que parecieron más evidentes para mostrar los perjuicios que puede acarrear a la sociedad la sobrestimación de los pasos de un héroe por la historia. (ITURRIETA 2003, p. 9-10)

Para além do valor acadêmico, as investigações de Carrera Damas têm contribuído com as disputas político-sociais da atualidade. À vista disso, é difícil escrever qualquer história sobre o bolivarianismo que não tangencie sua leitura. Uma vez que o autor segue pautando os marcos das interpretações sobre o culto a Bolívar, é relevante pormenorizar alguns de seus argumentos centrais com a intenção de demonstrar seus limites.

Para indagar os trabalhos de Carrera Damas, este artigo busca fundamentos nas críticas à História das ideias esboçadas 
nas obras de Elias José Palti $(2007,2014)$ e nas impressões de John Pocock (2003) sobre os estudos das linguagens políticas. Sem fugir à importância de Carrera Damas, com este debate pretende-se refletir acerca de outros caminhos para os estudos sobre o bolivarianismo. Para tanto, dois pontos de análise são motrizes: refletir sobre as relações da historiografia do culto a Bolívar com a História das ideias, e sobre o problema da compreensão do culto heroico como prostração nacional.

\section{Reflexōes sobre o culto a Bolívar como História das ideias}

A lógica historiográfica que rege a interpretação de Carrera Damas sobre o culto bolivariano merece uma análise detalhada. O ponto inicial de grande parte de suas elucidações é derivado de seu posicionamento acerca das ideias vigentes na República Liberal Democrática. Esse é o caso da suposição de que a vigência da imagem de Bolívar significaria a perpetuação da projeção do passado sobre o presente. Segundo seu argumento, atualmente pode-se observar a atuação de uma forma aperfeiçoada da ideologia do culto, que ao longo do tempo carregou consigo toda sorte de conservadorismo, autoritarismo e atraso, tanto em sua composição quanto em seus usos (CARRERA DAMAS 2003, p. 318-319).

Sua argumentação desenrola-se sob uma visão total do processo sócio-histórico nacional, demarcando oposição à precedente história-pátria venezuelana que se concentrava em eventos-chave. Essa proposição é notável, por exemplo, em Una nación llamada Venezuela $(1997)^{5}$, quando o autor afirma que a exposição da investigação sobre a história nacional deveria ser feita a partir de um marco integral, conforme seu entendimento do que é história enquanto ciência social (CARRERA DAMAS 1997, p. 12). Essa constante de sua obra tem como consequência uma narrativa que apresenta, ao venezuelano, as especificidades de sua nacionalidade em categorias amplas e perduráveis. 
A disposição em investigar o processo histórico a partir de um aspecto integral e a ênfase na busca pelo peculiar nacional aparecem também em El culto a Bolívar (2003). Nesse trabaIho, há uma preocupação em estabelecer uma síntese temporal amparada na História das ideias:

\begin{abstract}
Si la captación de la unidad del momento-hecho histórico se revela difícil y laboriosa por la vastedad de sus límites, existe un orden histórico en que aquel se refleja ya de una manera sintética, y es el orden da las ideas históricas, entendidas no como mero producto de la realidad histórica, ni como principios activos de la misma, sino como expresión, como pantalla en que se proyecta su realidad, como reflejo sintético de su pluralidad parcelaria. En este sentido la historia de las ideas se construiría utilizando como material la representación ideológica del cuadro histórico que han realizado los hombres. (2003, p. 25, grifos do autor)
\end{abstract}

Para evitar seguir os vultos de representações ideológicas, o autor sugere "[...] mantener una constante referencia al acontecer histórico [...]." (2003, p. 25). Contudo, os empenhos mais explícitos que se podem observar nesse sentido são a tomada de testemunhos literários na qualidade de referências da projeção ideológica sobre o acontecimento histórico e o arranjo entre a ideologia em sua forma pura e a ideologia atuante ${ }^{6 .}$ Ou seja, há um afastamento da análise dos sentidos que o culto tem no debate público, como se esses sentidos pudessem ser aferidos a partir de fontes textuais isoladas.

A argumentação de Carrera Damas não demonstra uma preocupação metodológica em localizar os enunciados em seus contextos ou nas discussões públicas da época. Por exemplo, amparado exclusivamente nas crônicas de Fermín Toro (1843) sobre o funeral de Bolívar em Caracas em 1842, o autor afirma que a imagem do Libertador foi empregada pelo presidente conservador Antonio Páez (1790-1873) como um fator de governo. O que decorre na interpretação da cerimônia enquanto elemento para manipulação dos sentimentos populares, a fim de ocultar a dissenção sociopolítica nacional resultante da fundação do Partido Liberal em 1840 (CARRERA DAMAS 2003, p. 57-60).
6 - Aqui a investigação de uma ideologia atuante não significa uma análise de um campo efetivamente pragmático, senão numa nova roupagem da dicotomia ideia-realidade. 
Essa perspectiva sintetizadora da realidade histórica acaba por eclipsar a oposição dos liberais à narrativa oficial da celebração. Ao privilegiar a leitura de Fermín Toro (1843) como representação ideológica do momento histórico, Carrera Damas deixa de analisar o discurso de um dos mais importantes porta-vozes do Partido Liberal, Antonio Leocadio Guzmán (1883)7. Em artigo ao periódico El Venezolano, Gúzman contradisse o discurso institucional, ao construir pontes entre a imagem histórica de um Bolívar liberal e grupos que contestavam a administração do Partido Conservador, tais como os veteranos do exército libertador que haviam se amotinado contra o governo em 1835 (GUZMÁN 1883, p. 446, 449). Ou seja, em 1842 o culto a Bolívar já se apresentava em disputa, logo não poderia ser afirmado como um resumo da pluralidade do contexto histórico, uma vez que se tratava de um fenômeno polissêmico.

É interessante expor esse movimento de Carrera Damas às críticas que Elias Palti realiza sobre problemas metodológicos da História das ideias: "[...] la misma piensa los textos en términos de postulados y representaciones pero les atribuye funciones que son propias a los usos del lenguaje, a su dimensión pragmática [...] " (PALTI 2014, p. 12). Isto é, seu método tende a buscar uma condição pragmático-contextual num objeto semântico, o que induz a "[...] describir las ideas en términos de significados y proposiciones atribuyéndole, sin embargo, funciones que son propias de su uso." (PALTI 2007, p. 293).

Outro exemplo procedente desse método nos trabalhos de Carrera Damas é a possibilidade de inclusão do presidente Hugo Chávez (1954-2013) na lista do arquétipo de Anti-Héroes Nacionales-padrotes de la Patria (CARRERA DAMAS 2007). Aqui, o autor traça um vínculo determinante entre o que considera uma ideologia do culto heroico e o sentido despótico e autoperpetuador dos discursos dos governantes venezuelanos. Pelo mesmo motivo e ao mesmo modo que lideranças autocratas do século XIX (Antonio Guzmán Blanco ${ }^{8}$ ) e da primeira metade do século XX (Eleazar López Contreras ${ }^{9}$ ) - embora em situações reconhecidamente distintas -, o recurso à ideolo-

\begin{abstract}
7 - 0 referido texto foi publicado originalmente em 1842 no periódico El Venezolano, e foi republicado em 1883 numa coletânea de editoriais de Leocadio Guzmán no mesmo jornal.
\end{abstract}

8 - Guzmán Blanco (1829-1899) foi um líder político-militar hegemônico na Venezuela entre 18701888. Seu mandonismo, o guzmanato, pode ser compreendido entre três mandatos presidenciais: Septenio (18701877), Quinquenio (1879-1884) e Bienio (1886-1888).

9 - Lopez Contreras (1883-1973) foi o primeiro presidente eleito depois da ditadura de Juan Vicente Goméz (1908-1935). Apesar da aparência de democrática, seu mandato (19351941) foi marcado por expurgos, exílios políticos e perseguição às esquerdas. 
gia é argumento aceitável para identificar no discurso chavista acepções de autoritarismo e ideias antidemocráticas, de tal forma que sua ação política aparenta ser não mais que uma versão atuante da ideologia perfeccionada.

Para Palti, um sentido do discurso, qualquer que seja, não pode ser localizado no seu nível semântico (ideias), pois ali encontram-se apenas suas proposições. Tal caracterização só poderia advir de uma análise no nível pragmático da linguagem, ou seja, no enunciado, no que se fazia ao dizer o que se disse:

En definitiva, no bastaría ya con comprender el significado de aquellos postulados o ideas contenidos en texto en cuestión sino que habría de poder reconstituir su sentido, al cual es una función del contexto de enunciación particular en que se produjeron los mismos; es decir, aun cuando las ideas contenidas en los textos sean las mismas, el sentido de ellas variará según quien las dice, cuándo, cómo, etc. (PALTI 2014, p. 12, grifo do autor)

A aplicação da crítica de Palti ao trabalho de Carrera Damas não implica negar a presença de sentidos de qualquer discurso, mas, sim, de compreender que o enfoque de sua problematização não pode ser feito a nível de ideologia sob o risco de encontrar apenas atuações de uma abstração a-histórica. Só a observação do discurso na prática de seu contexto político possibilita a compreensão conjunta de seus sentidos e significados.

De forma análoga, em El culto a Bolívar, o recurso ao exame da realidade histórica por meio do "[...] reflejo sintético de su pluralidad parcelaria" (CARRERA DAMAS 2003, p. 25, grifo do autor) - isto é, sua expressão ideológica - incide num problema similar. Ao invés de propor uma análise unitária do processo histórico, como sugere Carrera Damas, esse artifício estigmatiza os acontecimentos históricos vinculados ao culto a Bolívar enquanto imagens de ideologia envolvida na permanência do caudillismo, do atraso, da passividade popular. É razoável que o autor perceba traços de uma mentalidade nas citações de testemunhos historiográficos e literários com 
as quais trabalha. Contudo, isso não certifica sua relação com práticas antiquadas, visto que a análise não corresponde ao aspecto semântico, mas à esfera contextual-pragmática.

Por isso, é importante destacar que há alternativas a Carrera Damas e seu exame de um grande arco temporal em função de uma estrutura ideológica preconcebida. A crítica de Luis Castro Leiva (1984), ao debater a polêmica que El culto a Bolívar provocou no âmbito de sua publicação, aponta que tanto as leituras da obra como as de seus opositores se preocupavam mais em discutir a adequação e a eficácia sociopolítica das ideias do culto bolivariano do que se as concepções em circulação são, de fato, o pensamento de Bolívar, e não abstrações constantemente manipuladas. O compartilhamento entre Carrera Damas e seus críticos segue noutros aspectos, como o pressuposto de que os textos falam por si próprios a partir da literalidade de seus sentidos e, nesse ponto, incidem sobre a realidade (CASTRO LEIVA 1984, p. 81-82). Contra esse tipo de encadeamento, Castro Leiva propõe um olhar para o enredo linguístico no qual são formulados os enunciados:

El individuo que piensa es, en este sentido, el soporte del «decir» del pensamiento en un momento dado de su historia: es este sentido una biografía intelectual. Y ésta sólo es inteligible en la medida en que se recuperen las condiciones ambientales de la semántica y retórica de su «decir». (CASTRO LEIVA 1984, p. 88)

A perspectiva de Castro Leiva guarda certa semelhança com o coetâneo contextualismo da Escola de Cambridge, em especial com John Pocock (2003). Ambos percebem a necessidade de recuperar os domínios nos quais os textos são formulados e encarar a enunciação sob a forma de ato. Pocock, preocupado em definir o métier do historiador, sugere uma abordagem elucidativa. Centrado no reconhecimento das linguagens como contextos nos quais se dão performances (atos de fala), o autor propõe uma história "[...] da retórica, e não tanto da gramática, do conteúdo afetivo e efetivo do discurso, e não tanto de sua estrutura " (2003, p. 67). Não à toa que 
Pocock encare mentalités e ideologias como leituras monolíticas das situações linguísticas, e, em contraposição, busque estratégias mais atentas às suas polissemias. Isso se desenvolve no seu interesse pelo constante devir que define as relações entre linguagem e enunciação. Seu raciocínio centra-se na percepção da trama de linguagens como suporte para o discurso de um autor, que, por sua vez, no ato de enunciação, estressa a dinâmica da linguagem em uso, ainda que sua intenção $a$ priori tenha sido a manutenção do mesmo idioma.

O culto a Bolívar e a gestão simbólica de seus sentidos têm características eventuais e efêmeras, se comparadas à durabilidade das ideias na análise de Carrera Damas, de forma que a metodologia de Pocock se aplica à investigação da obra desse autor, posto que atenta às brevidades próprias ao debate político. Noutros termos, ao ponderar o bolivarianismo como uma linguagem política, é fundamental afastar-se de discussões totalizantes, a fim de compreender como

[...] as novas circunstâncias geram tensões nas velhas convenções, [como] a linguagem acaba sendo usada de novas maneiras, ocorrem transformações na linguagem em uso, e [como] é possível imaginar esse processo conduzindo à criação e à difusão de novas linguagens. (POCOCK 2003, p. 76)

A relação entre o método de Pocock e a crítica de Castro Leiva fornece certa segurança para propor que a interpretação do culto como trama linguística deve estar atenta à sua capacidade de mediação. Nessa circunstância, é possível afirmar, por ora, que as análises de testemunhos históricos precisam estar implicadas em mais que reafirmar uma explicação do domínio da elite político-social, já que, ao se utilizarem da linguagem bolivariana, os autores estão esboçando posicionamentos políticos ante as contendas públicas em discussão na sociedade. Mais que exprimir um controle, o emprego do bolivarianismo pode sugerir que há um campo não concluído, não encerrado, no qual os atores políticos lançam suas jogadas na expectativa de serem ouvidos e referendados. 


\section{Um desvio na trajetória venezuelana? Problemas da compreensāo do culto heroico como prostraçāo nacional}

Outra problemática a ser considerada em relação ao exame intelectual do bolivarianismo localiza-se na constante acusação de deslocamentos políticos, ideológicos e morais, provocados por uma suposta inadequação: a do culto a Bolívar em relação ao tempo histórico no qual ocorre. Tal lógica permitiu à historiografia contemporânea da Venezuela projetar sobre o culto um espectro de tradicionalismo, conservadorismo e legitimação da autocracia, desenhando sua imagem como âncora político-ideológica que impede o avanço pertinente das ideias progressistas do século XIX. A naturalização do destino à modernidade é, por si só, uma questão precária nesse raciocínio. Todavia, é igualmente complicadora, embora menos evidente, a rede de pressupostos que atribui ao culto a Bolívar um sentido de anomalia justificadora do que Carrera Damas considera experiências problemáticas da política venezuelana. É, portanto, uma tarefa essencial destacar e pormenorizar os apriorismos utilizados para construção dessa lógica.

Nos trabalhos de Carrera Damas, essa formulação é uma premissa importante para as conclusões gerais nas quais se engajou, sendo preservada em sua obra, inclusive nas publicações recentes. Um exemplo é seu artigo Entre el héroe nacional-padre de la patria y el anti-héroe nacional-padrote de la patria (2007), no qual aponta a impropriedade do emprego de uma ideologia pré-moderna a uma realidade moderna e a decorrência de efeitos negativos dessa relação. Nesse escrito, a persistência do modelo de Héroe nacional-Padre de la Patria - no qual a autocracia e a arbitrariedade são pensadas como necessárias à conjuntura das guerras de independência - é entendida como inapropriada aos tempos da República Liberal $^{10}$, em vista de seu papel na sustentação do arquétipo do Anti-Héroe Nacional-padrote de la Patria. Assim,
10 - No texto, República Liberal se refere a todo contexto pós1830, quando a Venezuela emerge como Estado independente da Grã-Colômbia. 
[...] Esa conexión ha consistido en que, de manera sospechosamente consecuente, el primero ha sido utilizado como fuente de legitimación ideológica, y de aval político, del segundo, pero sin haberse atrevido este último a reivindicar, expresamente, lo pautado por el primero en su proyecto de Constitución para la República Bolívar, sobre la conveniencia de un Presidente con derecho a designar su sucesor, conformándose así un híbrido de la monarquía constitucional con la república. No obstante, ha sido la práctica del resultado de esta hibridación, más cercana de la monarquía absoluta que de la constitucional, el estilo de mando - que no de gobierno - , de esa suerte de monarcas republicanos. (CARRERA DAMAS 2007, p. 204).

Tal explicação cria uma forte sensação de coerência, sobretudo quando é utilizada para explanar a atual conjuntura política da Venezuela. Conforme mencionado, ao fim da lista histórica de Anti-Héroes Nacionales-padrotes de la Patria estaria Hugo Chávez "[...] establecido por la tradición como Némesis de las aspiraciones democráticas de la sociedad venezolana, presentes desde 1863" (CARRERA DAMAS 2007, p. 203). Porém, há pontos a se ter em conta sobre a montagem dessa alegação. Para tanto, é oportuno retomar as críticas que Palti faz à História das ideias, ciente das divergências que outros autores colocam ante sua análise ${ }^{11}$.

Um ponto de partida é o postulado da dicotomia tradição-modernidade. Em análise da obra Modernidad e independências (1992), de François-Xavier Guerra, Palti observa que a tradição historiográfica da História das ideias interpreta quaisquer distanciamentos do tipo ideal liberal-ilustrado enquanto uma "[...] recaída en una visión tradicionalista, que expresaría la persistencia de patrones culturales o sociales pre-modernos" (2007, p. 154). Desta forma, configura-se uma desordem interpretativa ao se deslocar aspectos discursivos do substrato histórico que Ihes possibilitam enunciação para associá-los a um contexto precedente. Palti elabora uma síntese desse quadro ao apontar que:

[...] Mientras que los "modelos" de pensamiento ("Ios tipos ideales"), considerados en sí mismos, aparecen como [...] defi-
11 - À exemplo de Aguilar Riviera (2008, p. 183): "Es exagerado $[\ldots]$ que los enfoques $[\ldots]$ en la historia de las ideas en América Latina generan necesariamente una ansiedad por la 'particularidad' que nunca pueden satisfacer. Algunos lo ha hecho, otros no." 
nibles a priori - de allí que toda "desviación" de éstos (el logos) solo pueda concebirse como sintomática de alguna suerte de pathos oculto (una cultura tradicionalista y una sociedad jerárquica) que el historiador debe des-cubrir - , las culturas locales, en tanto sustratos permanentes (el ethos hispano), son, por definición, esencias estáticas. E resultado es una narrativa pseudohistorica que conecta dos abstracciones. (2007, p. 38)

Buscar nos nacionalismos latino-americanos a persistência de uma tradição local é, na verdade, assumir a impossibilidade de encontrar essa ideologia na forma de ideia "puramente" liberal ilustrada. Assim, o diagnóstico de desajustes nos nacionalismos latino-americano se baseia em duas falácias: 1. Que é razoável a retirada de um discurso de sua condição histórica de enunciação para vinculá-lo à expressão da permanência de uma base anterior; e 2. Que isso explique a inadequação dos nacionalismos nas Américas, baseado na miragem de que a ideia de nação é uma "[...] entidad abstracta, homogénea y unificada". (PALTI 2007, p. 151)

Essa crítica também é aplicável a Carrera Damas, em especial ao constante trabalho de vinculação entre as práticas políticas do século XIX e as ideologias que circulam no contexto da emancipação. À primeira vista, essa conexão não parece remeter à tradição hispânica ou colonial, já que sua formulação se situa na conjuntura de ruptura com a Europa e seus poderes. No entanto, para destacar seu caráter mais retrógrado, o autor trata de enfatizar dois aspectos: a fratura, causada pelos processos de independência, não foi total, ainda que em determinadas conjunturas tenha sido enunciada dessa forma, e a conexão com o período colonial pôde ser estabelecida de formas menos diretas ou se situou em territórios inesperados, nos quais a negação ao vínculo com a tradição "pré-moderna" espanhola não fora sequer cogitada, como o próprio Carrera Damas persistentemente salienta. Embora entre as independências e o período colonial houvesse mais diálogos que disrupções, não se pode dizer que isso repercutiu em decadência ou anacronismo para os processos de consolidação dos Estados pós-emancipação. Para reconhecer os efeitos dessa ilusão 
nos estudos sobre o bolivarianismo, é fundamental demarcar como na obra El culto a Bolívar (2003) se constrói uma vinculação entre culto e tradicionalismo.

Para Carrera Damas, houve três interesses históricos na origem da idolatria a Bolívar: a unidade nacional, enquanto ordem político-social interna; a governabilidade, isto é, garantir o compromisso da população em geral com a possibilidade de gerir o Estado; e a superação nacional, a fim de prover o empenho do povo com os projetos governamentais de edificação da nação (2003, p. 44). Esses encargos estavam a serviço do que $o$ autor considera uma oligarquia conservadora, assinalada como participante de uma tradição pré-moderna numa série de assertivas. Primeiro, Carrera Damas assinala que os artífices da independência podiam ser identificados enquanto caudillos (2003, p. 47). A seguir, aponta que a elite governante da Venezuela reagiu à escalada de políticas de cunho liberal-radical na Grã-Colômbia com a separação da confederação e a reintegração de setores criollos realistas à vida pública (2003, p. 48). Noutro trecho afirma que, no decorrer do pós-separação, o argumento político da oligarquia foi uma oposição ao liberalismo radical, contrariando, inclusive, ambições de setores ditos mais evoluídos da sociedade (2003, p. 52). E, por fim, explica que, na arena política, a oposição ao liberalismo radical - que reivindicava o papel de continuador do programa da emancipação - terminou por legar aos conservadores a imagem de "[...] guardianes de las relíquias del orden colonial tan combatido" (2003, p. 53).

O estabelecimento de tal relação é consequência - e ao mesmo tempo legitimação - da dedução de Carrera Damas sobre o culto, visto que "[...] su función ha sido la de disimular um fracaso y retardar um desengaño, y la ha cumplido satisfactoriamente hasta ahora." (2003, p. 42). Assim, as correlações entre o culto e os hábitos sociopolíticos tradicionais (identificáveis no serviço a políticas da oligarquia conservadora) dificultariam o avanço do liberalismo na Venezuela, prolongando a inadequação das ideias da emancipação à realidade 
local por meio do não cumprimento do programa social das independências.

As próprias definições do bolivarianismo em culto de un pueblo e culto para el pueblo estão carregadas de associações com o atraso. O primeiro molda-se em elementos de uma tradição triunfalista que celebra os líderes de vitórias militares, a exemplo de Bolívar que, depois da vitória da Batalha de Boyacá em 1819, foi intitulado Padre de la Patria (CARRERA DAMAS 2003, p. 95-96). O outro é um culto "[...] institucionalizado, orquestrado e dirigido por el Estado [...] al servicio de la política oficial imperante" (2003, p. 308). Segundo o autor, na transição entre ambos houve um processo ideológico de consagração da imagem de Bolívar: a perfectibilização da representação heroica elevada até um plano inalcançável deu margem à identificação com elementos do sagrado cristão, como providência divina, missão celestial e até mesmo Deus, de forma que se estabeleceu "[...] una religión, la segunda religión, llamada a complementar en el orden cívico la función que la otra realiza en el orden espiritual y moral " (2003, p. 64, grifo nosso). O que está implícito nessa argumentação é que o culto - para além de servir a políticas tradicionais - seria, em si, concebido por elementos de uma ordem "pré-moderna", ou seja, um triunfalismo militar inflado por uma liturgia espelhada no catolicismo.

Carrera Damas escolhe ver o pior dos dois mundos, pois sua busca é irremediavelmente pela contradição, pelo engodo e pelo retrocesso que o culto provoca na sociedade venezuelana. Isso é o que consegue observar e enfatizar permanecendo refém da busca pelo atavismo, mesmo quando o culto é apropriado pelo Estado, sem conseguir notar o bolivarianismo enquanto instância comunicacional venezuelana na modernidade. Para desbaratar esse direcionamento, é essencial evidenciar os reducionismos que essa lógica proporciona ao examinar as suposições do autor sobre o culto de un pueblo e o culto para el pueblo. 
Carrera Damas aponta que a transição de um modelo para o outro esteve implicada nos usos do bolivarianismo enquanto instrumento de dominação social por parte das elites governantes e das instituições do Estado venezuelano. Em seu argumento, a transição entre culto popular e culto estatal se deu precisamente com a festa de repatriação dos restos mortais de Bolívar em 1842 (CARRERA DAMAS 2003, p. 283-285). Empregando esse marco como fio condutor, este artigo propõe uma análise, a partir das festas bolivarianas, das inconsistências em sua interpretação.

\subsection{O culto de un pueblo}

Nesse momento, é necessário retornar à suposição de que as manifestações cultuais anteriores a 1842 seriam uma forma de culto de un pueblo a fim de demonstrar sua imprecisão. Ao menos no que se trata de festas bolivarianas, é duvidoso encará-las enquanto mostra natural da vontade geral. A exemplo da Entrada triunfal de Bolívar em Caracas em 1827, essas festas tiveram um ordenamento previamente definido, que gerava uma série de sentidos para os significados pretendidos por alguma esfera de poder. Em 1827, o ritual manteve um perceptível diálogo com a crise política da Cosiata do ano anterior. Mesmo a festa de San Fernando de Apure, em 1832, os Funerais do Libertador em Ganare, em 1836, ou a celebração do dia natalício de Bolívar pelo Colegio Nacional de Guayana, em 1848 - efemérides citadas por Pino Iturrieta (2003, p. 2834) para justificar o caráter popular dos primórdios do culto - foram celebrações preparadas com antecedência pelo poder político local ou delegadas por esse a alguma instituição governamental ou social. Ainda que todos os mencionados episódios mantivessem uma relação mais religiosa que cívica com o Libertador, não é possível defini-los pela fórmula de un pueblo, uma vez que não foram eventos regidos pela espontaneidade popular, mesmo que tenham sido compostos, em alguma medida, por efervescências coletivas. 
Também nas ocorrências de festas mais próximas à voluntariedade, como, por exemplo, a Entrada de Bolívar em Caracas, no ano de 1813, depois da Campaña Admirable e da capitulação de Domingos Monteverde, a ausência de um protocolo oficial não significou que tal evento foi movido pela - ou percebido na forma de - efervescência coletiva. E ainda que assim o fosse, a forma como foi narrada pela imprensa alterou definitivamente seus sentidos, dilatando suas percepções em questão de tempo e de espaço. Isso quer dizer que muitas narrativas de periódicos, por exemplo, moldaram para o público letrado a compreensão de uma manifestação popular em resposta às demandas do poder local instituído. Sem a publicação de 26 de agosto de 1813 da Gazeta de Caracas, editada por Vicente Salías, não seria possível definir que o povo de Caracas entendeu a pomposa acolhida a Bolívar em contraponto "[...] al silencio profundo [...] la tristeza y el dolor" (SALÍAS 1813, p. 4) da Entrada de Monteverde na cidade no início daquele mesmo ano. De modo análogo, se a sequência "[...] homenages [sic] sinceros de todo un pueblo a quien acaba de liberar, manifestados por la misma tierna sensibilidad [...]" (SALÍAS 1813, p. 4) for interpretada como uma adesão geral e definitiva dos caraquenhos ao programa da libertação, em algo se deve ao empenho narrativo do periódico. Esse mesmo fervor não se viu em 1815, quando Pablo Morillo, novo comandante das tropas realistas, tomou Caracas sem qualquer resistência, contando inclusive com o apoio da Gazeta de Caracas, agora sob o editorial do realista José Domingo Diaz (CONWAY 2006, p. 80).

É compreensível, portanto, que além do sentimento coletivo, a gestão dos sentidos da festa também atendia às pautas e às necessidades do debate público e, portanto, não estava restrita às comoções populares. Por outro lado, isso não significa que o povo foi um espectador passivo, senão que acessou de uma forma distinta a comunicação social. De uma forma ou doutra, a ação simbólica popular e a atribuição de sentidos à festa na arena político-institucional não são excludentes. Em oposição à fórmula de Carrera Damas, pode-se encontrar 
um entendimento das polissemias do bolivarianismo na interpretação do culto enquanto linguagem política, de modo que seus usos variados e seu reconhecimento e circulação social estariam fundamentados no que explica Pocock:

[...] quanto mais institucionalizada for uma linguagem e quanto mais pública ela se tornar, mais ela estará disponível para os propósitos de diversos locutores, articulando diversas preocupações. Essa diversificação terá origem no interior do grupo governante, onde comumente há um intenso debate em andamento. Mas ela pode não permanecer confinada aos limites da intelligentsia [...]. Podemos encontrar casos em que uma linguagem foi difundida para além dos limites do relacionamento original entre governantes e governados, no qual ela foi criada: casos em que estará sendo enunciada por outros governantes para outros governados, por governantes incertos quanto a quem estão governando, por governados incertos de quem os governa ou com que autoridade, e até mesmo por revolucionários usando-a em seus esforços por derrubar um governo. (2003, p. 68-69)

Caso a distinção entre de un pueblo e para el pueblo fosse abordada como uma diferenciação entre as respectivas escalas local e nacional das efemérides - o que implicaria uma oposição factível entre os eventos de 1813 e 1827, de um lado, e a festa de 1842, do outro - a lógica de Carrera Damas serviria para explicar os alcances comunicacionais do bolivarianismo. Mas não é esse o tratamento destinado à questão, visto que o autor define

La organización institucional del culto ha significado una transformación de la naturaleza del mismo. Su inicial condición de culto de un pueblo, como forma directa de expresión de admiración y de amor, se ha trocado en la organización de un culto para el pueblo, dotado de una liturgia que tiene por finalidad cuidar del objeto de culto y promover su desarrollo. (CARRERA DAMAS 2003, p. 375)

Em resposta a esse posicionamento, a perspectiva de Pocock possibilita acessar cada texto no qual fora empregado o bolivarianismo, notando que suas oscilações derivam do contexto de debate político em que se insere. Dessa forma, pode-se 
fugir da busca por exemplos de inadequações ou permanências de tradicionalismos, ao mesmo tempo que se compreende as transformações do culto sem tentar enquadrá-lo numa liturgia ou finalidade específica. Afinal, como percebe Nikita Harwich (2003), Bolívar é um herói usado para - e por - todas as causas.

\subsection{O culto para el pueblo}

O conceito de ideologia em Carrera Damas aparece a reboque de uma leitura marxista, que o leva a considerar a estrutura cultuária conforme a imposição unilateral de domínio por parte das elites locais. Não à toa que Teresa Torres (2009, p. 57) o considera como formulador da interpretação histórico-marxista do mito bolivariano, uma narrativa da luta das elites socioeconômicas para se restabelecer no poder político após a independência, aplacando os ânimos populares por meio do inegável prestígio social de Simón Bolívar. A leitura do culto a Bolívar enquanto condição de predomínio social é uma constante no pensamento de Carrera Damas. Já coetâneo do governo de Hugo Chávez, em 2005, no ato da Conferência inaugural da Cátedra José de Oviedo y Baños, o autor destacou el culto heroico decimonónico ${ }^{12}$ como um dos debates nos quais os jovens historiadores venezuelanos deveriam se aprofundar, justificando-se pela seguinte argumentação:

Éste se ha confirmado, en tiempos recientes, como una gran amenaza contra la conciencia histórica del venezolano. Tal ha sido el resultado, ahora exacerbado, de la conversión de este culto en una suerte de segunda religión, estructurada sirviéndole de eje el culto a Bolívar. A su vez, este último ha sido transformado de un culto del pueblo en un culto para el pueblo, y por lo mismo en una ideología oficial consagratoria del atraso en el orden de las ideas sociopolíticas, y en una sima de la conciencia histórica del venezolano en la cual se hunde buena parte de su creatividad. (CARRERA DAMAS 2006, p. 5)

Isto posto, é perceptível que Carrera Damas supõe que o crônico desajuste da consciência nacional venezuelana está
12 - Decimonónico é um adjetivo em espanhol para se referir ao século XIX, sua tradução mais próxima no português seria oitocentista. 
implicado no peso que o culto a Bolívar exerce contra o seu progresso "natural" ou histórico, como se sua essência tradicionalista atuasse na refração das ideias liberais à realidade venezuelana. Esse raciocínio the possibilita atribuir aos usos do culto uma sorte de conservadorismo e autoritarismo, já que sua presença implicaria basicamente o atavismo da herança pré-moderna aquém da consideração dos contextos históricos nos quais são apresentados e os debates políticos que integram.

Em paralelo, o autor reafirma uma miragem biográfica de Bolívar ao postular um herói recuperável para o paradigma liberal-democrático, um Bolívar possível sob um olhar crítico da história. Como argumenta na recente entrevista concedida a Arce e Tedeschi:

[...] hay un culto a Bolívar que ese sí es genuino... Es lo que practica gente como yo. Yo admiro a Bolívar. Pero lo admiro como un gran hombre, como un gran guerrero, como un pensador, pero también como un hombre. Es decir, él vivió situaciones muy difíciles, que cometió graves errores [...]. Es decir, era un hombre que estaba inmerso en una gran polémica, en una gran discusión. Pero era un hombre que estaba aprendiendo y lo extraordinario es que fue capaz de sintetizar toda la teoría de la Independencia de las colonias hispanas, del imperio hispano-americano, de diseñar una concepción, una política, una estrategia y llevarla a la práctica. Eso lo singulariza como un hombre realmente excepcional... con los errores, por supuesto, y también errores graves, pero con aciertos de tan amplio que superan con mucho lo que podríamos considerar que fueran errores o desaciertos. Pero debemos respetarlo de su integridad, no deificarlo. (ARCE; TEDESCHI 2015, p. 202, grifos nossos)

A partir desse diálogo, é possível ponderar que, mesmo sob condenações, a lógica do culto encontra ecos na forma como o autor interpreta o passado nacional. Suas reflexões parecem reféns do Bolívar totêmico - que, apesar das pretensões de secularização, segue como objeto histórico integral -, cuja análise é capaz de esboçar a expressão de toda uma sociedade ou de todo um período. Noutros termos, os dois Bolívares descritos por Carrera Damas, o divino e o humano, estão 
ancorados na ilusão de que as historicidades da imagem do Libertador e seus usos podem ser apreendidos de forma integral e permanente.

Um reflexo desse entendimento é a relação que se traça entre o culto e a opressão social. Na leitura de Carrera Damas, o autoritarismo/bolivarianismo aparece como um problema quase que exclusivo da ação das elites por meio da imposição ideológica, ou seja, um dispositivo de controle social. Essa circunstância praticamente exime o povo de responsabilidade, atribuindo-Ihe um papel passivo no teatro político. A investigação a partir de uma abordagem contextual do bolivarianismo propõe um olhar distinto para essa arena, visto que o culto denotava esforços de intelectuais e governos empenhados em conquistar adesão coletiva por meio de uma complexa gestão de valores políticos para símbolos mais ou menos consagrados ante o público geral. As festas bolivarianas são situações exemplares para esse argumento.

O culto a Bolívar significou um investimento de energia, não só no exercício da construção de verdades, mas também em alocar elementos exteriores que as convalidem de formas lógicas ou afetivas, mas não propriamente autoritárias. ${ }^{13} \mathrm{Com}$ base na observação das festas, pode-se presumir que $o$ apoio popular à autoridade é a contraparte do compromisso com programas políticos imediatistas, cujas alegações centrais gravitavam em torno da resolução das crises cotidianas e históricas da sociedade venezuelana. Nesse aspecto, as crônicas dos eventos festivos difundiram, solidificaram e direcionaram argumentos do casamento entre povo e governo nas pautas celebradas com entusiasmo popular. Esses eventos estiveram imersos em debates com consequências imprevisíveis, embora limitados pelas linguagens em uso pelos seus debatedores.

As narrativas das principais festas bolivarianas do século XIX são exemplos do modo com que se empregou a linguagem bolivariana com intenção de promover soluções para dramas sociopolíticos de seus contextos. A seguir, há uma concisa descrição das transições de significados em cada temporalidade,

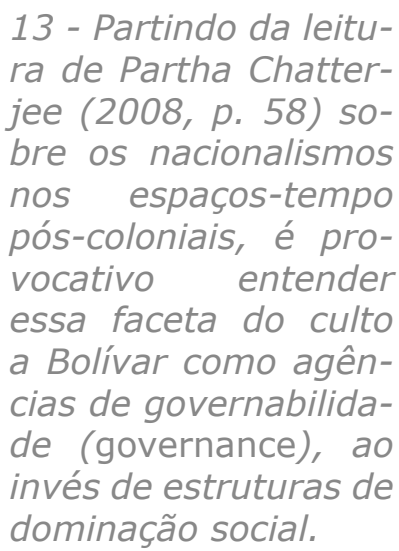

13 - Partindo da leitura de Partha Chatterjee (2008, p. 58) sobre os nacionalismos nos espaços-tempo pós-coloniais, é provocativo entender essa faceta do culto a Bolívar como agências de governabilidade (governance), ao dominação social. 
a fim de exemplificar esse raciocínio, entretanto não será dada atenção ao debate social vigente em cada situação, visto que tal mérito demanda uma longa pormenorização e análise de cada evento, necessidade cuja eficácia deve ser melhor trabaIhada num artigo à parte.

Na Sucinta descripcion de la entrada del Libertador Presidente en Caracas, el 10 de enero de 1827, Valentin Espinal (1827) narrou uma propensão do povo à pacificação e reunião com o programa bolivariano da Grã-Colômbia, logo após a rebelião separatista da Cosiata:

A todos es constante por una muy sensible experiencia la situación lamentable á que se hallaba reducida Venezuela á principio del mes de diciembre próximo pasado, á consecuencia de las alteraciones sufridas en nuestro sistema político. Crueles males se palpaban, y el horizonte presagiaba mayores desgracias en lo sucesivo; y para que fue se más deplorable nuestro estado, el único remedio [Bolívar] que divisaba la observación atenta de las cosas, existía á millares de leguas, en las riberas del Pacífico, ocupado en el bien de las repúblicas que había formado, y cuya gratitud parecía empeñada en retenerle en su seno para siempre. Allí, pues, se fijaban las miradas dirigidas por el deseo de consuelo: allí los suspiros anhelantes en que prorrumpía el amor á la patria.

[...] Al imperio del dolor, pronta y mágicamente sucede el dulce reinado de un júbilo cordial. El pueblo, en los trasportes de tan vivos afectos enérgicamente manifiesta hasta qué grado había aumentado su año al Héroe el carácter de redentor de las desdichas domésticas, que veía unírsele al glorioso título de Libertador, que condecora las virtudes patrióticas con que distintas veces extirpó la opresión. Los ciudadanos, discurriendo por las calles enagenados, comprimen el aire con el eco incesante de sus entusiasmados víctores al criador y salvador de la patria; y el gozo ocupa y se explica hasta en el recinto escondido de las habitaciones privadas. (ESPINAL 1827, p. 1-2).

Seu texto iniciava-se com uma apresentação da sociedade venezuelana à beira do abismo de uma violenta guerra civil, para, em seguida, reafirmar Bolívar como liderança capaz de reconstruir os laços de integração social, quase colapsados, através da sua presença e da simbólica do ritual em sua ho- 
menagem. Desse modo, o Libertador foi calcado como ícone vivo da integração e reitor de um povo que se desviara do seu caminho.

Em Descripción de los honores fúnebres consagrados a los restos del Libertador Simón Bolivar, de Fermín Toro (1843), pode-se observar um esforço por aludir à manutenção da unidade nacional e da ordem política. Pautas que respondiam, desta vez, ao rearranjo de poder entre a elite governante, fraturada pela fundação do Partido Liberal em 1840.

Essa retórica se organiza a partir da descrição do processo de reinvindicação dos restos mortais de Bolívar pela Venezuela, o que havia sido barrada pelo Congresso em 1833 e 1839. Em 1842, a finalização do empasse se concretiza por influência do então presidente Antonio Páez, cujo intento pode ser compreendido como uma medida de precaução: era necessário empreender o translado do corpo do herói, antes que a oposição liberal o fizesse em meio à construção de uma plataforma simbólica para alçar-se ao poder. Como fora expresso em suas palavras, "[...] nadie debe traerlos sino la Nación á quien pertenecen, porque á ella se consagró exclusivamente. Ellos son propriedad de Venezuela." (PÁEZ apud TORO 1843, p. 7).

Dali em diante, os atos nos quais o povo exprimiria seu apresso pela memória de Bolívar deveriam ser respaldados pelo voto nacional, ou seja, no pacto entre Congresso e Executivo. Assim, para que os louvores ao Libertador não pudessem ser empunhados como armas da oposição, contemplou-se uma viragem simbólica em dois atos de esquecimento: 1 . Omitia-se a participação de Páez no decreto de desterro a Bolívar em 1829, que assinara como Jefe Supremo de Venezuela; 2. Apagava-se a reticência do Legislativo e o seu bojo antibolivariano, que se recusara, por duas vezes, a recuperar a memória de Bolívar.

Entretanto, a retórica de Toro subverteu o arranjo dessa contradição ao destacar a função de Páez na resolução do debate. No relato das discussões de 1833 e 1839 sobre a realização dos funerais de Bolívar, o autor conferiu valor de passiona- 
lidade aos atos do Legislativo, concomitantemente atribuía-se serenidade às petições do Executivo. Em paralelo, o recurso de falar como representante popular foi amplamente empregado por Toro para sustentar a afirmação de que o povo estava em conformidade com as ações do Executivo e que fora a pressão exercida por essa circunstância que convencera o Legislativo a abandonar seus receios quanto ao retorno do prócer. Em seu relato, a aprovação da lei que permitiu a restituição do corpo do herói à pátria foi exposta como uma vitória popular expressa por meio da ação de Páez contra o titubear ou o desafio do Congresso:

[...] allí fue el gran reto: allí durante doce años vinieron sucesivamente á escollarse el error, la envidia y la calumnia: allí fueron vencidos los que se creyeron fuertes, y se menguaron los que se llamaron grandes: allí en fin, la voz de un pueblo, por un órgano incorruptible, proclamó á Bolívar Fuerte y Grande! El silencio de doce años se rompió noblemente. Una sola voz se oyó, hubo un solo pensamiento: los honores á Bolívar son honras á la patria. (TORO 1843, p. 8).

Por seu turno, em Las fiestas del primer centenario del libertador Simón Bolivar, de Ramón Hurtado Sánchez (1883), o relato gravitava em torno da comemoração do progresso e do projeto de modernização nacional dos governos de Antonio Guzmán Blanco. Mesmo antes de 1883, Guzmán Blanco e seu séquito já empreendiam uma política de memória centrada na relação entre Caracas, o culto heroico e o progresso. Pedro Calzadilla (1999, p. 129) demonstra que as festas bolivarianas do primeiro governo Guzmán Blanco (1870-1877) possuíam atributos de instrumento pedagógico. Em meio à ritualização, os grupos articuladores evidenciavam, para a população em geral, os avanços que a sociedade sofrera sob a política de ordem moral e civilização (1999, p. 118). Guzmán Blanco tentara imprimir sobre Caracas uma imagem de metrópole moderna, porém, em nenhum outro evento foi tão eficaz quanto nas celebrações do Centenário.

As transformações apresentadas nas festividades cumpriram o objetivo de prover lógica ao progresso experimentado e esperado. Todos os episódios comungaram da celebração à 
memória bolivariana. Profeta ou iniciador de um projeto que só pudera ser finalizado nas circunstâncias do Guzmanato, essa imagem foi referendada por Hurtado Sánchez, quando indicou que Guzmán Blanco fora capaz de realizar o progresso que Bolívar desejou para sua pátria:

Pasemos ahora á describir las Grandes Fiestas que nos hemos propuesto, cuyas glorias de haberlas efectuado estaban reservadas á Guzmán Blanco, á ese Hombre Ilustre con cuyo gobierno laza á la Patria por los vastos horizontes del progreso; de aquel progreso que anheló para ella su mismo Libertador y que hoy empieza por fin a la Patria á disfrutar. [...] El ha sabido medir la magnitud del Héroe que las ha motivado y su alta transcendencia, y por eso no ha omitido sacrificio alguno para que la Patria en su actual gobierno se mostrase digna de su Libertador y del Pueblo que libertó. (HURTADO SÁNCHEZ 1883, p. 15).

Desse modo, embora apresentem a mesma linguagem e tratem de gerir os mesmos símbolos, cada crônica esteve preocupada em ofertar respostas aos debates públicos de suas conjunturas políticas. $\mathrm{O}$ exame das festas possibilita observar que o culto a Bolívar não foi simplesmente uma forma de dominação social. De modo mais genérico, enunciados que tocassem as promessas não realizadas da libertação - ou que afirmassem que a independência estaria incompleta pelo evidente descumprimento do programa original de Bolívar e, portanto, precisaria ser refeita ou finalizada - , eram retóricas constantemente reafirmadas dentro dos limites da linguagem cultual. Em contrapartida, falar em antibolivarianismo seria inteligível nesse idioma. Neste trabalho enfatiza-se que não houve necessariamente uma vinculação direta entre autoritarismo, manipulação popular e o culto a Bolívar. Na verdade, existiu uma gama de comunicações sociais embasadas no bolivarianismo, cuja multivocalidade indica a probabilidade de encontrar nessas interlocuções, também, enunciados de conteúdos despóticos. Contudo, uma leitura que frise apenas o autoritarismo estaria ignorando aspectos culturais, sociais e políticos, reduzindo o fenômeno a uma estrutura uniforme de dominação política de mão única: do dominador para o dominado. 


\section{Consideraçōes finais}

Em suas investigações, Carrera Damas é perspicaz ao afirmar uma relação entre militarismo-autoritarismo e a permanência social do culto. Entretanto, suas explicações, voltadas para o controle social, concentram-se nos efeitos de longa duração do fenômeno. O propósito das reflexões apresentadas neste texto foi perceber as possibilidades de encarar o bolivarianismo por meio de seus usos comunicacionais. Isso significa apostar que outros percursos são possíveis, em especial aqueles que se concentram nos eventos do culto.

É inegável que Carrera Damas se configura em paradigma central da análise do bolivarianismo. Quando afastado de pressupostos problemáticos da História das ideias, encontra-se em seus trabalhos um importante literato da história social venezuelana e um baluarte original de leituras que seguem pertinentes. Mesmo the rendendo críticas, esse lugar singular faz com que seja arriscado abrir mão de utilizá-lo como um referencial historiográfico. Ademais, de sua perspectiva derivam outros olhares para o culto que possibilitam entender a espessura que o fenômeno ocupa na sociedade venezuelana. Elias Pino Iturrieta e Manuel Caballero, para citar alguns autores, cujos estudos mais recentes prestam os devidos tributos a Carrera Damas.

Sua leitura, entretanto, é insuficiente para compreender a pluralidade e a polissemia do bolivarianismo. Além dos problemas interpretativos, é válido salientar as dificuldades relativas ao pioneirismo de sua obra e ao tempo decorrido desde suas primeiras publicações, ao passo em que é cada vez mais importante que se busquem alternativas para compreender o bolivarianismo, especialmente por se tratar de um fenômeno que segue se reinventando.

Compreender o culto a Bolívar a partir da perspectiva das linguagens políticas oferece um horizonte para investigações que se concentrem nos usos, nas transformações ou nas mul- 
tivocalidades do culto heroico. São caminhos pelos quais se pode entender porquê, atualmente, a reivindicação do herói persiste por todas as partes. Afirmar que o culto a Bolívar não foi utilizado exclusiva e diretamente como expressão da dominação social possibilita perceber, de forma mais ampla, o seu emprego para forjar enunciados das mais diversas tendências, a fim de mediar visões de mundo e conquistar adesão para diversos projetos políticos. Em suma, ao observar o passado por meio de um fenômeno tão fluido, mais relevante que condená-lo é desvelar o que - como, por que e para quem - foi dito por meio dele.

\section{REFERÊNCIAS}

AGUILAR RIVERA, José Antonio. El tiempo de la teoría: la fuga hacia los lenguajes políticos. A Contracorriente, $v$. 6 , n. 1, p. 179-188, 2008.

ARCE, Anatólio Medeiros; TEDESCHI, Losandro Antonio. El culto a Bolívar y la historiografía venezolana: talla con el historiador Germán Carrera Damas. História da Historiografia, n. 19, p. 200-211, 2015. Disponível em: https://www.historiadahistoriografia.com.br/revista/article/ view/965. Acesso em: 26 jun. 2019.

CABALLERO, Manuel. Por qué no soy bolivariano: una reflexión antipatriótica. Caracas: Alfadil, 2007.

CARRERA DAMAS, Germán. Una nación Ilamada Venezuela. Caracas: Monte Avila Editores Latinoamericana, 1997.

CARRERA DAMAS, Germán. El culto a Bolívar: Esbozo para un estudio de la historia de las ideas en Venezuela. Caracas: Alfadil Ediciones, 2003.

CARRERA DAMAS, Germán. El bolivarianismo-militarismo: Una ideología de reemplazo. Caracas: Ala de Cuervo, 2005. 
CARRERA DAMAS, Germán. Achicar la sentina de la historiografía venezolana. Conferencia inaugural de la cátedra José de Ovidedo y Baños. Escuela de Historia. Universidad Central de Venezuela. Procesos Históricos, no de julio, 2006.

CARRERA DAMAS, Germán. Entre el héroe nacional-padre de la patria y el anti-héroe nacional-padrote de la patria. ARBOR Ciencia, Pensamiento y Cultura, v. CLXXXIII, n. 724, p. 203-210, 2007. Disponível em: http://arbor. revistas.csic.es/index.php/arbor/article/view/91. Acesso em: 26 jun. 2019.

CASTRO LEIVA, Luis. El historicismo político bolivariano. Revista de Estudios Políticos (Nueva Epoca), n. 42, p. 71-100, 1984. Disponível em: http://www.cepc.gob.es/ publicaciones/revistas/revistaselectronicas?IDR =3\&ID$\mathrm{N}=201 \& \mathrm{IDA}=16199$. Acesso em: 26 jun. 2019.

CASTRO LEIVA, Luis. La Gran Colombia, una ilusión ilustrada. Caracas: Monte Avila Editores, 1985.

CASTRO LEIVA, Luis. De la patria boba a la teología bolivariana: Ensayos de historia intelectual. Caracas: Monte Avila Editores, 1991.

CALZADILLA, Pedro. El olor de la pólvora: Fiestas patrias, memoria y Nación en la Venezuela guzmancista 18701877. Caravelle, v. 73, n. La fête en Amérique Latine, p. 111-130, 1999. Disponível em: https://www.persee. fr/doc/carav_1147-6753_1999_num_73_1_2856. Acesso em: 26 jun. 2019.

CHATTERJEE, Partha. La nación en tiempo heterogéneo y otros estudios subalternos. Buenos Aires: Siglo Veintiuno Consejo Latinoamericano de Ciencias Sociales (CLACSO), 2008.

CHÁVEZ FRÍAS, Hugo. Agenda alternativa bolivariana.

Caracas: Ediciones Correo del Orinoco, 2014. 
CONWAY, Christopher. Letras combatientes: género epistolar y modernidad en la GACETA DE CARACAS, 18081822. Revista Iberoamericana, v. LXXII, n. 214, p. 7791, 2006. Disponível em: https://revista-iberoamericana. pitt.edu/ojs/index. php/Iberoamericana/article/viewFile/62. Acesso em: 26 jun. 2019.

ESPINAL, Valentin. Sucinta descripción de la entrada del Libertador Presidente en Caracas, el 10 de enero de 1827. Caracas: Imprenta del Valentin Espinal, 1827.

GUERRA, François-Xavier. Modernidad e independencias: Ensayos sobre las revoluciones hispánicas. Madrid: Ed. Mapfre, 1992.

GUZMÁN, Antonio Leocadio. Editoriales de "El Venezolano" (Tomo II). Caracas: Imprenta al vapor de "La Opinión Nacional", 1883, 4 t.

HARWICH, Nikita. Un héroe para todas las causas: Bolívar en la historiografía. Iberoamericana, v. III, n. 10, pp. 7-22, 2003. Disponível em: https://journals.iai.spk-berlin.de/index.php/iberoamericana/article/view/600. Acesso em: 26 jun. 2019.

HURTADO SÁNCHEZ, Ramón. Las fiestas del primer centenario del libertador Simón Bolivar. Caracas: Impr. Editorial, 1883.

ITURRIETA, Elias Pino. El divino Bolivar: Ensayo sobre una religión republicana. Caracas: Libros de la Catarata, 2003.

PALTI, Elias José. El tiempo de la política: El siglo XIX reconsiderado. Buenos Aires: Siglo Veintiuno Editores Argentina, 2007.

PALTI, Elias José. ¿Las ideas fuera de lugar?: Estudios y debates en torno a la historia politico-intelectual latinoamericana. Buenos Aires: Prometeolibros, 2014. 
POCOCK, John. Linguagens do ideário político. São Paulo: Editora da Universidade de São Paulo, 2003.

SALAS DE LECUNA, Yolanda et al. Bolívar y la historia en la conciencia popular. Caracas: Universidad Simón Bolívar, Instituto de Altos Estudios de América Latina, 1987.

SALCEDO-BASTARDO, José Luis et al. Visão e revisão de Bolívar. Rio de Janeiro: Agir, 1976.

SALÍAS, Vicente. Entrada triunfante del General Bolívar en Caracas. Gazeta de Caracas, Caracas, 26 de ago de 1813, p. 4.

SUÁReZ figueroA, Naudy. Puntofijo y otros puntos. Fundación Rómulo Betancourt, 2006.

STRAKA, Tomas. ¿Hartos de Bolívar? La rebelión de los historiadores contra el culto fundacional. Boletín de la Academia Nacional de la História, v. 365, p. 51-91, 2009. Disponível em: http://www.anhvenezuela.org.ve/ sites/default/files/boletines/BANH_365.pdf. Acesso em: 26 jun. 2019.

TORO, Fermín. Descripción de los honores fúnebres consagrados a los restos del Libertador Simón Bolivar. Caracas: La imprenta de Valentin Espinal, 1843.

TORRES, Ana Teresa. La herencia de la tribu (Del mito de la Independencia a la Revolución Bolivariana). Caracas: Editorial Alfa, 2009. 


\section{AGRADECIMENTOS E INFORMAÇŌES}

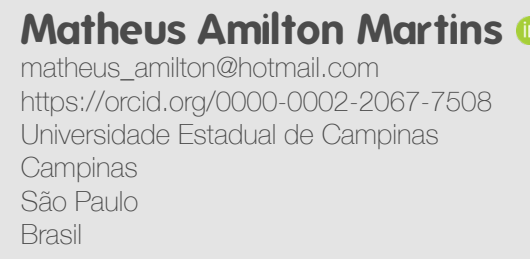

Pesquisa realizada com financiamento do CNPq, Conselho Nacional de Desenvolvimento Científico e Tecnológico.

Este artigo é derivado de discussões da dissertação de mestrado intitulada Festas para Bolívar? Entre projetos e sentidos nas comemorações dedicadas ao Libertador em Caracas (1827, 1842, 1883) defendida em 2018 na Universidade Estadual de Campinas (UNICAMP) e financiada pela CNPQ. $\mathrm{Na}$ presente versão, o texto foi aprimorado com o intuito de atender ao escopo de debates sobre teoria da história e historiografia. Agradeço às leituras e aos comentários de José Alves Freitas Neto, Thiago Biazzoto e Claudia Oliveira. 